Research Paper

\title{
Esophageal Cancer in Israel has Unique Clinico- Pathological Features: A Retrospective Study
}

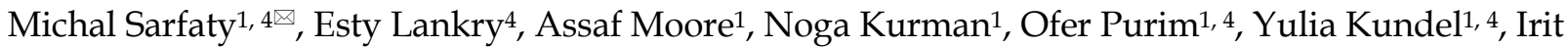

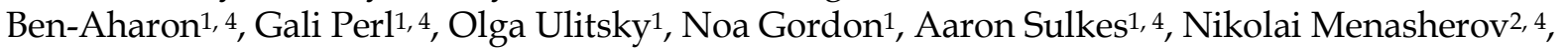 \\ Hanoch Kashtan ${ }^{3}, 4$, Baruch Brenner ${ }^{1,4}$ \\ 1. Institute of Oncology, Davidoff Center, Rabin Medical Center, Petach Tikva, Israel; \\ 2. Department of Surgery A, Rabin Medical Center, Petach Tikva, Israel; \\ 3. Department of Surgery B, Rabin Medical Center, Petach Tikva, Israel; \\ 4. Sackler Faculty of Medicine, Tel-Aviv University, Tel Aviv, Israel. \\ $\square$ Corresponding author \\ (c) Ivyspring International Publisher. This is an open access article distributed under the terms of the Creative Commons Attribution (CC BY-NC) license \\ (https://creativecommons.org/licenses/by-nc/4.0/). See http://ivyspring.com/terms for full terms and conditions.
}

Received: 2017.01.16; Accepted: 2017.04.26; Published: 2017.07.22

\begin{abstract}
Introduction: Data regarding esophageal cancer (EC) in Israel are limited. The aim of this study was hence to characterize this entity in the Israeli population and to compare it to the literature.

Patients/Methods: This is a retrospective study of all consecutive EC patients treated at our institution between 1997-2013. Data were retrieved from patients' medical files.

Results: Two hundred patients were included. The median age at diagnosis was 70.5 years; $63.5 \%$ were males; $63 \%$ were Ashkenazi Jews, $29 \%$ were Sephardic Jews, and $0.5 \%$ were Arabs. Squamous cell carcinoma (SCC) was predominant: $52 \%$ versus $45.5 \%$ with adenocarcinoma (ADC). SCC was common even in the distal esophagus (45\%). The overall 5 -year survival rate was $25.5 \%$. A temporal trend (2006-2013 vs 1997-2005) shows a decline in the proportion of SCC (47\% vs $63 \%$, $p=0.061)$ and a rise in ADC $(50 \%$ vs $33 \%, p=0.041)$, with a parallel decrease in patients' age (median: 68.5 vs 73 years, $p=0.014$ ). In the later period, patients received more treatment for localized and metastatic disease, with a trend for improved median survival (20.1 vs 14.9 months, $p=0.658$ ). Ashkenazi Jews were diagnosed at an older age than Sephardic Jews (median: 73 vs. 65 years, $\mathrm{p}=0.001)$, had a higher rate of family history of $\mathrm{Gl}$ cancer $(34 \%$ vs. $17 \%, \mathrm{p}=0.026)$ and a higher rate of cardiovascular co-morbidity ( $41 \%$ vs. $24 \%, \mathrm{p}=0.041)$.

Conclusion: EC in Israel represents an intermediate entity between the Western and the endemic subtypes, showing some unique features. These included delayed reversal of the SCCIADC ratio, commonness of SCC in the distal esophagus, prevalence of other malignancies and predominance of Ashkenazi ethnicity. The reason for these findings is unclear and its further evaluation is warranted.
\end{abstract}

Key words: Esophageal cancer, Squamous, Adenocarcinoma, Israel, Epidemiology

\section{Background}

Esophageal cancer (EC) comprises two histopathological subtypes: squamous cell carcinoma (SCC) and adenocarcinoma (ADC). The incidence rate of each histological subtype varies greatly according to lifestyle habits, socioeconomic and environmental factors, as reflected in the diversity between different geographic areas around the world.(1)
While the incidence of SCC tumors has declined several folds in Western countries, it remains stable in many geographic areas including Turkey, northern Iran, southern republics of the former Soviet Union, and northern China. In these endemic areas, SCC comprises the majority of EC, as opposed to only $40 \%$ of EC cases in the United States. Incidence rates may 
vary up to 200-fold between different populations in the same geographic area, mainly due to different cultural practices. In contrast to SCC, incidence rates of ADCs have increased substantially in Western countries. (2)

EC tumors are also classified according to the site of the tumor: upper (cervical), mid (thoracic), and lower (thoracic/gastroesophageal junction =GEJ). There is also a slight difference in the staging of each histologic type. SCC is the common histology of cervical and upper thoracic tumors, whereas ADC predominates in the distal esophagus and GEJ.(4)

There is a significant overlap between the treatment of esophageal ADC and SCC but some of the differences are of great importance. For example, while data on systemic chemotherapy for metastatic SCC is mostly limited to cisplatin/5-fluorouracil (5FU) combinations, treatment options for metastatic ADC include also taxanes, antracyclines and tyrosine kinase inhibitors ${ }^{(5)}$. In addition, while chemoradiation (chemoRT) for localized SCC may be a definitive treatment option, in localized ADC chemoRT primarily serves as neoadjuvant therapy to radical surgery(6).

EC is an uncommon disease in Israel, with an incidence rate of approximately 1.5 per 100,000 (7). Data on EC in Israel are scarce and are essentially derived from three reports, one from 1975, and two more recent ones $(2006,2009) .{ }^{(8-10)}$ While the first report, from over four decades ago, described individual patient data collected from their medical records, the two later reports described limited registry data. EC is usually treated in Israel according to methods and guidelines developed in Western countries, despite lack of sufficient evidence that the biology of the disease in Israel indeed resembles its counterpart in Western Europe and North America. Moreover, the existing data suggests diversity in the epidemiology of EC even between different Israeli subgroups. ${ }^{(8-10)}$

The aim of this study was therefore to define the epidemiological and clinicopathological features of EC in Israel at present, to evaluate how these have changed over time, and to compare the disease characteristics in Israel to those in the Western world and in the endemic regions.

\section{Patients and Methods}

In this retrospective study, the medical files of all consecutive patients with EC who were treated at the Institute of Oncology, Davidoff Center, Rabin Medical Center (RMC), between 1997 and 2013, were reviewed. The study protocol was approved by the
Rabin Medical Center's Ethics Committee (\#0469).

The study population was considered representative of the Israeli population since the Institute of Oncology at the RMC is centrally located and is one of the largest referral centers in Israel, treating over $15 \%$ of EC patients in the country, and due to the consecutive nature of the study cohort.

Individual patient information was collected from patient medical records and from the institutional electronic database. The data collected included epidemiology, clinical presentation, tumor characteristics at diagnosis, treatment information, and clinical course. The study was approved by the institutional ethics committee.

Statistical analysis of the database created was conducted according to standard methods. Overall survival (OS) was measured as the time interval between date of diagnosis and death or the last date the patient was known to be alive. OS was estimated using the Kaplan-Meier product limit method (11). Comparison of OS between groups was conducted using the log-rank test ${ }^{(12)}$. Multivariate analysis was done by Cox proportional hazard regression (13). P-values $\leq 0.05$ were considered statistically significant.

\section{Results}

\section{The study population}

Two hundred EC patients were included in the study. The main patient characteristics are shown in Table 1. A 2:1 male predominance was observed. The median age at diagnosis was 70.5 years (range: $36-92$ ); $43 \%$ had a family history of cancer and 19\% had other malignancies. SCC was the predominant histology overall: $52 \%$ versus $45.5 \%$ with ADC. While in the upper/middle esophagus, the SCC:ADC ratio was 90:10, in the lower esophagus ADC became the more frequent histology and this ratio changed to 55:45. Most patients (66\%) were diagnosed with advanced disease, either locally ( $45 \%$ ) or distant (21\%).

\section{Patient outcome}

With a median follow up of 68 months (range: 14-226 months), 138 patients (69\%) had died of disease, $5(2.5 \%)$ are alive with disease and $34(17 \%)$ are alive with no evidence of disease. The median OS was 18.9 months (95\% CI: 15.6-22.1 months) and the 5-year OS rate was $25.5 \%$. Univariate analysis for OS identified multiple known adverse prognostic factors, including older age, male gender and advanced stage at diagnosis. On multivariate analysis, only advanced age and stage retained their significant impact on OS. 
Table 1. Patient and Tumor Characteristics $(\mathrm{N}=200)$

\begin{tabular}{|c|c|c|}
\hline Variable & $\mathrm{N}$ & Valid \% \\
\hline \multicolumn{3}{|l|}{ Age (years) } \\
\hline Median, range & \multicolumn{2}{|c|}{$70.5(36-92)$} \\
\hline \multicolumn{3}{|l|}{ Gender } \\
\hline Female & 73 & 36.5 \\
\hline Male & 127 & 63.5 \\
\hline \multicolumn{3}{|l|}{ Ethnic origin } \\
\hline Ashkenazi Jews & 121 & 63 \\
\hline Sephardic Jews & 55 & 29 \\
\hline Other ${ }^{1}$ & 15 & 8 \\
\hline Missing Data & 9 & \\
\hline \multicolumn{3}{|l|}{ Family history } \\
\hline GI malignancy & 27 & 15 \\
\hline Non-GI malignancy & 50 & 28 \\
\hline Missing Data & 21 & \\
\hline \multicolumn{3}{|l|}{ Co-malignancy } \\
\hline GI malignancy & 6 & 3 \\
\hline Non-GI malignancy & 32 & 16 \\
\hline \multicolumn{3}{|l|}{ Co-morbidity } \\
\hline Cardiovascular & 66 & 33 \\
\hline Diabetes & 36 & 19.5 \\
\hline Peptic disease & 53 & 26.5 \\
\hline Smoking & 101 & 50.5 \\
\hline Alcoholism & 14 & 7 \\
\hline \multicolumn{3}{|l|}{ Presenting symptom/sign } \\
\hline Dysphagia & 162 & 81 \\
\hline Odynophagia & 57 & 28.5 \\
\hline Bleeding & 26 & 13 \\
\hline Weight loss & 140 & 70 \\
\hline \multicolumn{3}{|l|}{ Performance status } \\
\hline $0-2$ & 172 & 96 \\
\hline $3-4$ & 7 & 4 \\
\hline Missing Data & 21 & \\
\hline \multicolumn{3}{|l|}{ Location } \\
\hline Upper & 14 & 7 \\
\hline Middle & 48 & 24 \\
\hline Lower & 90 & 45 \\
\hline GEJ & 48 & 24 \\
\hline \multicolumn{3}{|l|}{ Histology } \\
\hline Squamous cell & 102 & 52 \\
\hline Adenocarcinoma & 89 & 45.5 \\
\hline NOS & 2 & 1 \\
\hline Other & 3 & 1.5 \\
\hline Missing Data & 4 & \\
\hline Tumor differentiation & & \\
\hline Well-Moderately differentiated & 84 & 55 \\
\hline Poorly differentiated-Anaplastic & 68 & 45 \\
\hline Missing Data & 48 & \\
\hline T stage & & \\
\hline T0-2 & 22 & 15 \\
\hline T3-4 & 128 & 85 \\
\hline Missing Data & 50 & \\
\hline N status & & \\
\hline No & 76 & 38 \\
\hline $\mathrm{N}+$ & 124 & 62 \\
\hline M status & & \\
\hline M0 & 163 & 81.5 \\
\hline M1 & 37 & 18.5 \\
\hline AJCC TNM stage & & \\
\hline Stage 0 & 2 & 1 \\
\hline Stage I & 9 & 5 \\
\hline Stage II & 48 & 28 \\
\hline Stage III & 77 & 45 \\
\hline Stage IV & 37 & 21 \\
\hline Missing Data & 27 & \\
\hline Metastatic sites at diagnosis & & \\
\hline Lymph nodes & 134 & 67 \\
\hline Soft tissue & 13 & 6.5 \\
\hline Bone & 33 & 16.5 \\
\hline Liver & 44 & 22 \\
\hline Lung & 40 & 20 \\
\hline Peritoneum & 13 & 6.5 \\
\hline CNS & 6 & 3 \\
\hline
\end{tabular}

Treatment setting

Stage I-III

Surgery only

Definitive ChemoRT

Surgery with Neo/adjuvant

Non-curative Treatment ${ }^{2}$

Metastatic - \# chemo lines

1

3

${ }^{1}$ Other includes Arab and Ethiopian origin

${ }^{2}$ Non-curative Treatment: supportive care, including palliative radiation or stent

\section{Comparison of two periods: 1997-2005 (58 pts), 2006-2013 (142 pts)}

To assess changes in patient and tumor characteristics over time we divided the study period into two equal time periods: 1997-2005 (58 patients) versus 2006-2013 (142 patients). Results are shown in Table 2. In recent years patients were diagnosed at a younger age (median 68.5 vs 73 years, $p=0.014$ ) and reported a higher rate of smoking $(p=0.033)$. In addition, the tumor histology was more likely to be ADC $(p=0.041)$ and this subtype became slightly predominant. More treatment was given in the later period, as more patients with localized disease received neoadjuvant or adjuvant treatment $(63 \%$ vs $18 \%, \mathrm{p}<0.0001)$ and less patients received palliative treatment only ( $8 \%$ vs $27 \%$, $\mathrm{p}=0.002$ ). Similarly, in the metastatic setting, 19\% were treated with 3 lines of therapy in the second period, as compared to none in the first one $(p=0.057)$. There was a trend for an improved patient outcome in the later period, but the difference was not statistically significant: median OS of 20.1 months versus 14.9 months $(p=0.658)$ for the entire group (Fig. 1A) and 12.5 months versus 6.3 months in patients with metastatic disease $(p=0.141)$ (Fig. 1B).

\section{Comparison of ethnicity}

Of those patients with reliable data on ethnicity (95\%), 63\% were Ashkenazi Jews, 29\% were Sephardic Jews, and $0.5 \%$ were Arabs. This predominance of Ashkenazi ethnicity remained unchanged over time.

A comparison between the two main Jewish ethnic groups is summarized in Table 3 and reveals several differences: Ashkenazi Jews were diagnosed at an older age (median: 73 vs. 65 years, $p=0.001$ ), had a higher rate of family history of GI-cancer (34\% vs. $17 \%, \mathrm{p}=0.026)$ and had a higher rate of cardiovascular co-morbidity ( $41 \%$ vs. $24 \%$, p=0.041). Interestingly, no difference in histology, location, or patient outcome was seen among the ethnic groups. 
Table 2. Comparing two periods

\begin{tabular}{|c|c|c|c|}
\hline Variable & $\begin{array}{l}1997-2005 \\
(\mathrm{~N}=58)^{1}\end{array}$ & $\begin{array}{l}2006-2013 \\
(\mathrm{~N}=142)^{1}\end{array}$ & p-value \\
\hline \multicolumn{4}{|l|}{ Age (years) } \\
\hline Median, range & $73(36-92)$ & $68.5(38-90)$ & 0.014 \\
\hline \multicolumn{4}{|l|}{ Gender } \\
\hline Female & $17(29 \%)$ & $56(39 \%)$ & \\
\hline Male & $41(71 \%)$ & $86(61 \%)$ & NS \\
\hline \multicolumn{4}{|l|}{ Ethnic origin } \\
\hline Ashkenazi Jews & $39(70 \%)$ & $82(62 \%)$ & NS \\
\hline Sephardic Jews & $16(29 \%)$ & $39(29 \%)$ & NS \\
\hline Other ${ }^{2}$ & $1(1 \%)$ & $12(9 \%)$ & NS \\
\hline \multicolumn{4}{|l|}{ Family history } \\
\hline GI malignancy & $12(23 \%)$ & $38(30 \%)$ & NS \\
\hline Non-GI malignancy & $5(10 \%)$ & $22(17 \%)$ & NS \\
\hline \multicolumn{4}{|l|}{ Co-malignancy } \\
\hline GI malignancy & $3(5 \%)$ & $3(2 \%)$ & NS \\
\hline Non-GI malignancy & $10(17 \%)$ & $22(16 \%)$ & NS \\
\hline \multicolumn{4}{|l|}{ Co-morbidity } \\
\hline Cardiovascular & $14(24 \%)$ & $52(37 \%)$ & NS \\
\hline Diabetes & $8(14 \%)$ & $31(22 \%)$ & NS \\
\hline Peptic disease & $15(26 \%)$ & $38(27 \%)$ & NS \\
\hline Smoking & $24(41 \%)$ & $77(54 \%)$ & 0.033 \\
\hline Alcoholism & $5(7 \%)$ & $9(6 \%)$ & NS \\
\hline \multicolumn{4}{|l|}{ Presenting symptom/sign } \\
\hline Dysphagia & $44(76 \%)$ & $118(83 \%)$ & NS \\
\hline Odynophagia & $15(26 \%)$ & $42(30 \%)$ & NS \\
\hline Bleeding & $3(5 \%)$ & $23(16 \%)$ & 0.038 \\
\hline Weight loss & $33(57 \%)$ & $81(57 \%)$ & NS \\
\hline \multicolumn{4}{|l|}{ Performance status } \\
\hline $0-2$ & $43(91 \%)$ & $128(98 \%)$ & \\
\hline $3-4$ & $4(8 \%)$ & $3(2 \%)$ & NS \\
\hline \multicolumn{4}{|l|}{ Location } \\
\hline Upper & $7(12 \%)$ & $7(5 \%)$ & NS \\
\hline Middle & $12(21 \%)$ & $36(25 \%)$ & NS \\
\hline Lower & $29(50 \%)$ & $61(43 \%)$ & NS \\
\hline GEJ & $10(17 \%)$ & $38(27 \%)$ & NS \\
\hline \multicolumn{4}{|l|}{ Histology } \\
\hline Squamous cell & $36(63 \%)$ & $66(47 \%)$ & $0.061(\mathrm{NS})$ \\
\hline Adenocarcinoma & $19(33 \%)$ & $70(50 \%)$ & 0.041 \\
\hline NOS & $2(4 \%)$ & $0(0 \%)$ & NS \\
\hline Other & $0(0 \%)$ & $3(3 \%)$ & NS \\
\hline \multicolumn{4}{|l|}{ Tumor differentiation } \\
\hline Well-Moderately differentiated & $25(61 \%)$ & $59(53 \%)$ & \\
\hline Poorly differentiated-Anaplastic & $16(39 \%)$ & $52(47 \%)$ & NS \\
\hline \multicolumn{4}{|l|}{ AJCC TNM stage } \\
\hline Stage I & $4(10 \%)$ & $5(4 \%)$ & NS \\
\hline Stage II & $8(20 \%)$ & $40(31 \%)$ & NS \\
\hline Stage III & $15(37.5 \%)$ & $62(47 \%)$ & NS \\
\hline Stage IV & $13(32.5 \%)$ & $24(18 \%)$ & 0.078 (NS) \\
\hline Treatment- Stage I-III & 45 & 118 & \\
\hline Surgery only & $11(24 \%)$ & $18(15 \%)$ & NS \\
\hline Definitive ChemoRT & $14(31 \%)$ & $17(14 \%)$ & 0.0016 \\
\hline Surgery with Neo/adjuvant & $8(18 \%)$ & $74(63 \%)$ & $<0.0001$ \\
\hline Non-curative Treatment ${ }^{3}$ & $12(27 \%)$ & $9(8 \%)$ & 0.002 \\
\hline \multicolumn{4}{|l|}{ Metastatic - \# chemo lines } \\
\hline 1 & $12(75 \%)$ & $39(66 \%)$ & NS \\
\hline 2 & $4(25 \%)$ & $8(14 \%)$ & NS \\
\hline 3 & $0(0 \%)$ & $11(19 \%)$ & 0.057 (NS) \\
\hline 4 & $0(0 \%)$ & $1(! \%)$ & NS \\
\hline \multicolumn{4}{|l|}{ Overall Survival (months) } \\
\hline Median (CI 95\%) & $14.9(9.5-20.4)$ & $20.1(18.1-22.2)$ & NS \\
\hline \multicolumn{4}{|l|}{ 3-year survival rate } \\
\hline & $29.9 \%$ & $30.2 \%$ & \\
\hline 5-year survival rate & & & \\
\hline & $26.7 \%$ & $23.1 \%$ & \\
\hline
\end{tabular}

${ }_{1}^{1}$ Percents were calculated from valid data.

Not including missing data, as in Table 1.

2 Other includes Arab and Ethiopian origin.

ChemoRT: Chemoradiation

${ }^{3}$ Non-curative Tx: supportive care, including palliative radiation or stent
Table 3. Comparison between the two main Jewish ethnic groups

\begin{tabular}{|c|c|c|c|}
\hline Variable & $\begin{array}{l}\text { Ashkenazi Jews } \\
(\mathrm{N}=121)^{1}\end{array}$ & $\begin{array}{l}\text { Sephardic Jews } \\
(\mathrm{N}=55)^{1}\end{array}$ & p-value \\
\hline \multicolumn{4}{|l|}{ Age (years) } \\
\hline Median, range & $73(38-92)$ & $65(36-90)$ & 0.001 \\
\hline \multicolumn{4}{|l|}{ Gender } \\
\hline Female & $37(31 \%)$ & $23(42 \%)$ & \\
\hline Male & $84(69 \%)$ & $32(58 \%)$ & NS \\
\hline \multicolumn{4}{|l|}{ Family history } \\
\hline Non-GI malignancy & $20(18 \%)$ & $4(8 \%)$ & \\
\hline GI malignancy & $38(34 \%)$ & $8(17 \%)$ & 0.026 \\
\hline \multicolumn{4}{|l|}{ Co-malignancy } \\
\hline GI malignancy & $3(2 \%)$ & $2(4 \%)$ & NS \\
\hline Non-GI malignancy & $22(19 \%)$ & $4(7 \%)$ & NS \\
\hline \multicolumn{4}{|l|}{ Co-morbidity } \\
\hline Cardiovascular & $49(41 \%)$ & $13(24 \%)$ & 0.041 \\
\hline Diabetes & $28(23 \%)$ & $8(15 \%)$ & NS \\
\hline Peptic disease & $33(27 \%)$ & $14(26 \%)$ & NS \\
\hline Smoking & $63(52 \%)$ & $29(53 \%)$ & NS \\
\hline Alcoholism & $8(7 \%)$ & $3(6 \%)$ & NS \\
\hline \multicolumn{4}{|l|}{ Presenting symptom/sign } \\
\hline Dysphagia & $99(82 \%)$ & $45(82 \%)$ & NS \\
\hline Odynophagia & $34(28 \%)$ & $18(33 \%)$ & NS \\
\hline Bleeding & $18(15 \%)$ & $7(13 \%)$ & NS \\
\hline Weight loss & $75(62 \%)$ & $29(53 \%)$ & NS \\
\hline \multicolumn{4}{|l|}{ Performance status } \\
\hline $0-2$ & $103(95 \%)$ & $46(96 \%)$ & \\
\hline $3-4$ & $5(5 \%)$ & $2(4 \%)$ & NS \\
\hline \multicolumn{4}{|l|}{ Location } \\
\hline Upper & $7(6 \%)$ & $4(7 \%)$ & NS \\
\hline Middle & $26(22 \%)$ & $12(22 \%)$ & NS \\
\hline Lower & $61(50 \%)$ & $23(42 \%)$ & NS \\
\hline GEJ & $27(22 \%)$ & $16(29 \%)$ & NS \\
\hline \multicolumn{4}{|l|}{ Histology } \\
\hline Squamous cell & $61(52 \%)$ & $26(47 \%)$ & NS \\
\hline Adenocarcinoma & $56(48 \%)$ & $26(47 \%)$ & NS \\
\hline NOS & $0(0 \%)$ & $2(4 \%)$ & NS \\
\hline Other & $0(0 \%)$ & $1(2 \%)$ & NS \\
\hline \multicolumn{4}{|l|}{ Tumor differentiation } \\
\hline Well-Moderately differentiated & $45(53 \%)$ & $23(52 \%)$ & \\
\hline Poorly differentiated-Anaplastic & $41(47 \%)$ & $21(48 \%)$ & NS \\
\hline \multicolumn{4}{|l|}{ AJCC TNM stage } \\
\hline Stage I & $5(5.5 \%)$ & $2(4 \%)$ & NS \\
\hline Stage II & $22(22 \%)$ & $17(33 \%)$ & NS \\
\hline Stage III & $45(45 \%)$ & $23(45 \%)$ & NS \\
\hline Stage IV & $27(27.5 \%)$ & $9(18 \%)$ & NS \\
\hline \multicolumn{4}{|l|}{ Overall Survival (months) } \\
\hline Median (CI 95\%) & $18.8(15.5-22.2)$ & $20.9(16.6-25.3)$ & NS \\
\hline \multicolumn{4}{|l|}{ 3-year survival rate } \\
\hline & $32.4 \%$ & $25.5 \%$ & \\
\hline \multicolumn{4}{|l|}{ 5-year survival rate } \\
\hline & $28.5 \%$ & $21.2 \%$ & \\
\hline
\end{tabular}

1 Percents were calculated from valid data.

Not including missing data, as in Table 1.

\section{Discussion}

The aim of this study was to characterize the main features of EC in Israel and to compare them to the literature on this disease. The RMC serves a large population in Central Israel, which represents the general Israeli population.

In fact this is the only current detailed, medical charts-based study on the Israeli population. When the comparison was possible, most of the clinic-pathological features of Israeli EC patients, as depicted in our study, were found to be in line with earlier reports on this population. Moreover, most of 
our findings are indeed similar to Western countries, including most of the epidemiological characteristics and the clinical features $(14,15)$. However, our study demonstrated several unique characteristics of the Israeli population; first and above all, we noted a significantly delayed reversal, compared to the Western countries, of the ratio between the two main histological subtypes of EC. This was accompanied by an unusual abundance of SCC histology in the distal esophagus. Second, we found a substantially high prevalence of other malignancies, mostly common cancers. Lastly, we noted a clear predominance of Ashkenazi Jews, one of the two major Jewish subgroups, which also exhibited several significant differences from the Sephardic Jews.

During the study period, EC underwent a profound global change in the ratio between its two main subtypes; while in Western countries there was a gradual reversal of the predominance from SCC to $\mathrm{ADC}$, with the later currently representing nearly $70 \%$ of all EC, the predominance of SCC remained unchanged in the endemic areas. The present study shows an intermediate pattern, with a clear decline in the proportion of SCC (63\% to $47 \%, \mathrm{p}=0.061)$ and a parallel increase in the proportion of ADC (33\% to $50 \%, \mathrm{p}=0.041$ ). Still, the rate of SCC is higher in Israel than in the Western world and the ratio between the two subtypes is nearly equal. Interestingly, SCC histology was common (45\%) even in the distal esophagus, unlike most Western series $(16,17)$. The main engine behind the histological redistribution of EC overtime is a change in lifestyle habits, mostly a decrease in the rate of smoking and increased rates of obesity and gastroesophageal reflux disease (GERD). We lacked detailed information on the patients' weight and prevalence of GERD, but there is a clear evidence for increased average weight and obesity in the general Israeli population ${ }^{(18)}$. With limited data, it appears that GERD too is becoming more common in Israel. We assume the increase in smoking rate overtime in our study is mostly a result of better patient questioning and reporting and not an actual increase in smoking habits, based on the clear decline of smoking in the general Israeli population ${ }^{(19)}$ and the decrease in SCC in this study. In spite of the relevant temporal changes in lifestyle habits in the Israeli population during the study period, clearly they could not provide the full explanation of the unique trend noted in our study and additional relevant factors need to be evaluated.

One such a potential factor would be the unique genetic background of the Israeli population. The Jewish Ashkenazi subgroup has been widely studied due to its known genetic predisposition to various diseases. These include relatively high rates of benign syndromes, such as Tay-Sachs and Gaucher, as well as inherited defects in DNA repair that increase susceptibility to various malignancies, such as breast, ovarian, colorectal and gastric cancers ${ }^{(20)}$.

The current study demonstrated an unequivocal majority of Ashkenazi Jews, comprising $63 \%$ of the study population, more than twice the rate of Sephardic Jews $(29 \%)$. This ratio is clearly different from the general population in the same age group, where the two subpopulations are almost equally represented (21). More detailed evaluation of these two Jewish subgroups revealed other differences as well. Interestingly, our findings are in line with our group's previous report on gastric cancer(22), whose biology overlaps significantly with that of EC, both showing
(A)

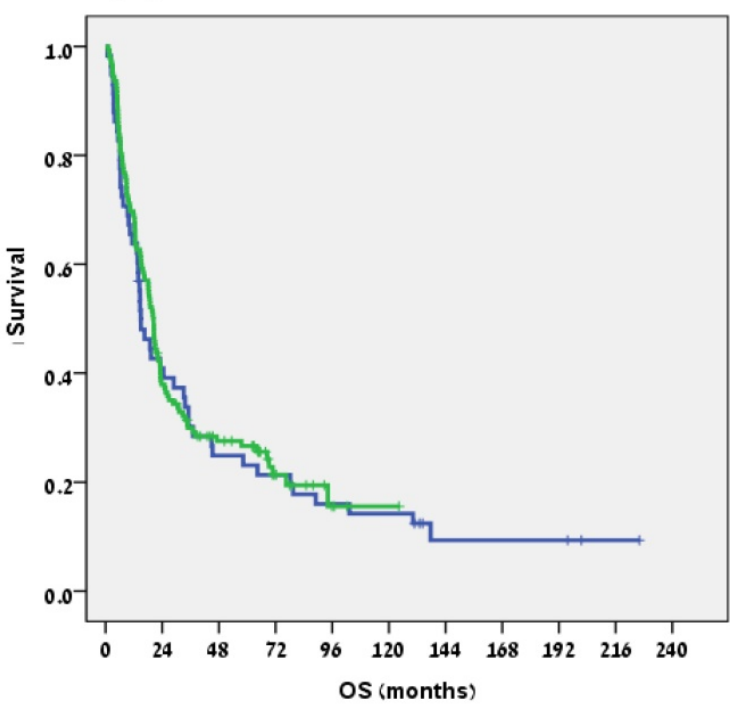

(B)

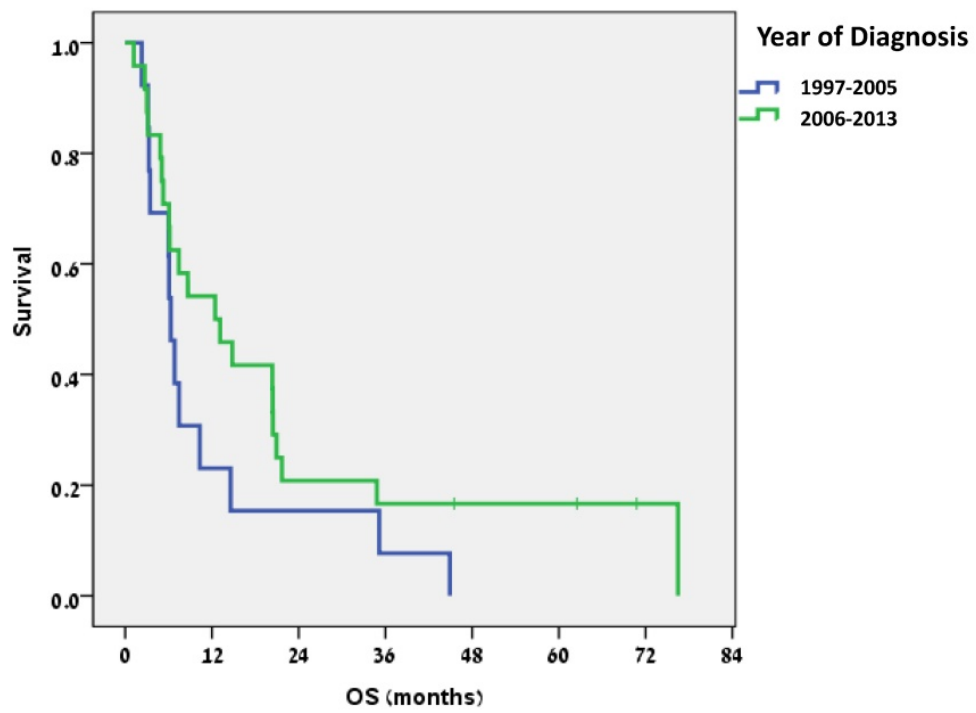

Figure 1. Overall survival for all patients (A) and for metastatic patients (B): Comparison of two periods (1997-2005 vs 2006-2013). 
that Ashkenazi Jews were diagnosed at an older age and had a higher rate of cardiovascular disease. With limited data, earlier reports also imply a higher incidence in Ashkenazi versus Sephardic Jews, and a low incidence in $\operatorname{Arabs}^{(11)}$. The predominance of Ashkenazi Jews and their high rate of family history of cancer may suggest genetic predisposition, as is known in other malignancies, including colorectal, breast, ovarian and gastric cancers ${ }^{(23,24)}$. More importantly, this genetic predisposition may lead to a different biology of EC in Israel, similar to the case of microsatellite instability (MSI)-related colorectal cancer (25) and breast cancer (BRCA) mutation-related breast and ovarian cancers (26).

A possible unique cancer-related genetic background can lead to a higher rate of other cancers. Indeed, we again found a high incidence of other malignancies among the Israeli patients (19\%), even higher than we previously reported $(12.7 \%)^{(27)}$. Interestingly, these other malignancies were mostly of non-GI origin, representing common cancers such as breast and prostate cancers, maybe suggesting a general susceptibility for cancer. Although familial tendency is a well-established risk factor for EC in high-incidence areas such as China (28), it has not been proven in Western countries such as the US and Sweden ${ }^{29,30)}$. In the present study family history of cancer was reported in $43 \%$ of cases. This finding is similar to that reported in studies conducted in the US and Sweden, showing family history of cancer in half of EC patients and in half of the controls $(29,30)$. No previous data was found on this matter regarding EC patients in Israel.

EC in Israel is currently being treated according to Western treatment guidelines. One of the drivers of this study was the need to evaluate the comparability of EC in Israel to its Western counterpart and to evaluate the appropriateness of utilizing strategies developed in Western countries to the Israeli patients. Our results suggest an extensive similarity, in most features of the disease, aside of several specific differences. More importantly, we did not identify any significant dissimilarity in the clinical aspects of the disease, including its presentation, response to treatment and outcome. Hence, it seems that adapting Western guidelines for our Israeli patients is reasonable, exercising caution due to the somewhat unique features in this population.

In summary, this is the first report describing individual patient data regarding EC in Israel in the last four decades. It demonstrated that most features of EC in Israel are similar to those reported in Western countries. Nevertheless, we identified several unique characteristics, including predominance of Ashkenazi Jews, high prevalence of other cancers, abundance of
SCC histology in the distal esophagus and delayed reversal of the SCC:ADC ratio. These findings suggest that EC in Israel may represent an intermediate entity between the Western and the endemic subtypes, with distinct characteristics and biology. Moreover, the strong relation to Ashkenazi ethnicity and the high incidence of other cancers may imply a unique genetic background and pathogenesis of EC in Israel and may impact our general understanding of the disease biology. At present, the etiology of the differences noted in this study is still unclear and further evaluation of these phenomena is needed. We have just initiated a follow-up study, as better understanding of the genetic background of EC in Israel may help to define high-risk populations in the country.

\section{Competing Interests}

The authors have declared that no competing interest exists.

\section{References}

1. Jemal A, Bray F, et al. Global cancer statistics. CA Cancer J Clin. 2011; 61: 69-90.

2. Posner MC, Minsky B, Ilson DH. Cancer of the esophagus. In: DeVita VT, Hellman S, Rosenberg SA, eds. DeVita, Hellman, and Rosenberg's Cancer: Principles and Practice of Oncology. 9thed. Philadelphia, Pa: Lippincott-Williams \& Wilkins. 2011; 887-923.

3. Brown LM, Devesa S, Fraumeni JF. Epidemiology of esophageal cancer. In: Posner M, Vokes EE, Weichselbaum RR, eds. Cancer of the Upper Gastrointestinal Tract. Hamilton, Ontario: BC Decker. 2002; 1.

4. Edge SB, Byrd DR, et al. Esophagus and Esophagogastric junction. In: AJCC Cancer Staging Manual (7th ed). New York, NY: Springer. 2010; 129-144.

5. Pasini F, Fraccon AP, et al. Targeted therapies for advanced and metastatic adenocarcinoma of the gastroesophageal junction: is there something new? Gastric Cancer. 2016; 19: 1-12.

6. Shridhar R, Imani-Shikhabadi R, et al. Curative Treatment of Esophageal Cancer; An Evidenced-Based Review. J Gastrointest Cancer. 2013; 44: 375-384.

7. [Internet] Esophagus (Gender and Subpopulation)- Cancer Incidence trends 1980-2013, Israel. National Cancer Registry, Ministry of Health, Israel. http://www.health.gov.il/UnitsOffice/HD/ICDC/ICR/CancerIncidence/P ages/Esophagus-.aspx

8. Mordechai S, and Modan B. Esophageal cancer in Israel: Selected clinical and epidemiological aspects. Am J Dig Dis. 1975; 20: 951-954.

9. Freedman, Laurence S., et al. Cancer incidence in four member countries (Cyprus, Egypt, Israel, and Jordan) of the Middle East Cancer Consortium (MECC) compared with US SEER. NIH Pub. No. 06-5873. Bethesda, MD: National Cancer Institute. 2006.

10. Rozen P, Liphshitz I, Barchana M. The changing epidemiology of upper gastrointestinal cancers in Israel: clinical and screening implications. Eur J Cancer Prev. 2009; 18: 191-198.

11. Kaplan EL, Meier P. Non-parametric estimation for incomplete observation. J Am Stat. 1958; 53: 457-481.

12. Mantel N. Evaluation of survival data and two new rank order statistics arising in its consideration. Cancer Chemother Rep. 1966; 50: 163-170.

13. Cox DR. Regression models and life tables. JR Stat SocSer B. 1972; 34: 187-220.

14. NCI. SEER18 2009-2013, All Races, Both Sexes. The Surveillance, Epidemiology, and End Results (SEER) Program of the National Cancer Institute Homepage.

15. Altekruse S, Kosary C, Krapcho M, et al. SEER Cancer Statistics Review, 1975-2008. National Cancer Institute. 2010.

16. Siewert JR, Ott K. Are squamous and adenocarcinomas of the esophagus the same disease? Semin Radiat Oncol. 2007; 17: 38-44.

17. Patel AN, Preskitt JT, et al. Surgical management of esophageal carcinoma. Bayl Univ Med Cent Proc. 2003; 16: 280.

18. [Internet] CBS: Israel. http://www.cbs.gov.il

19. [Internet] Ministry of Health: Israel. Revised May 2014. http://www.health.gov.il/PublicationsFiles/smoking_2013.pdf

20. Ostrer H, Skorecki K. The population genetics of the Jewish people. Human genetics. 2013; 132: 119-127.

21. Central Bureau of Statistics. Jews by continent of origin, 2014. Central Bureau of Statistics, Israel. 2014 
22. Dreznik A, Purim O, et al. Gastric cancer: biology and clinical manifestations in Israel. J Surg Oncol. 2012; 105: 316-322.

23. Petrucelli N, Daly MB, Feldman GL. Hereditary breast and ovarian cancer due to mutations in BRCA1 and BRCA2. Genet Med. 2010; 12: 245-259.

24. Friedenson B. BRCA1 and BRCA2 pathways and the risk of cancers other than breast or ovarian. Med Gen Med. 2004; 7: 60

25. Boland CR, Goel A. Microsatellite instability in colorectal cancer. Gastroenterology. 2010; 138: 2073-2087.

26. Narod SA. BRCA mutations in the management of breast cancer: the state of the art. Nat Rev Clin Oncol. 2010; 7: 702-707.

27. Spector R, Liphshitz I, Barchana M, et al. High incidence of non-upper aerodigestive primary tumors in patients with esophageal cancer. Dis Esophagus. 2008; 21: 718-722.

28. Gao Y, Hu N, Han X, et al. Family history of cancer and risk for esophageal and gastric cancer in Shanxi, China. BMC cancer. 2009; 9: 1.

29. Dhillon PK, Farrow DC, et al. Family history of cancer and risk of esophageal and gastric cancers in the United States. Int J Cancer. 2001; 93: 148-152.

30. Lagregen J, Weimin Y, Lindgren A, Nyren O. Heredity and risk of cancer of the esophagus and gastric cardia. Cancer Epidemiol Biomarkers Prev. 2000; 9: 757-60. 